\title{
Study of cobalt (II) biosorption on Sargassum sp. by experimental design methodology
}

\author{
F. Soleymani • M. H. Khani $\cdot$ H. Pahlavanzadeh • \\ M. Manteghian
}

Received: 16 June 2014/Revised: 2 November 2014/ Accepted: 22 December 2014/Published online: 20 January 2015

(C) Islamic Azad University (IAU) 2015

\begin{abstract}
In this study, the biosorption of cobalt (II) ions on Sargassum sp., brown algae, was investigated in a batch system. The combined effects of operating parameters such as biomass treatment, initial $\mathrm{pH}$, temperature, initial metal ion concentration, and biosorbent dosage on the biosorption of cobalt (II) ions on Sargassum sp. were analyzed using response surface methodology. The $\mathrm{Mg}\left(\mathrm{NO}_{3}\right)_{2}$ was used as a pretreatment agent for Sargassum sp. The optimum biosorption conditions were determined as Mg-trea-

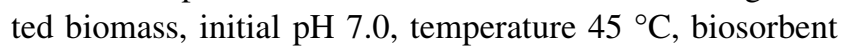
dosage $0.1 \mathrm{~g}$, and initial cobalt (II) concentration $300 \mathrm{mg} / \mathrm{l}$. At optimum biosorption conditions, the biosorption capacity of Mg-treated biomass for cobalt (II) ions was found to be $80.27 \mathrm{mg} / \mathrm{g}$ after 90 -min biosorption. The Langmuir and Freundlich isotherm models were applied to the equilibrium data. The results are best fitted by the Freundlich model.
\end{abstract}

Keywords Biosorption - Cobalt · Pretreated algae . Response surface methodology $\cdot$ Sargassum $\mathrm{sp}$.

\section{Introduction}

Cobalt containing compounds are widely used in many industrial applications such as mining, metallurgical,

F. Soleymani · H. Pahlavanzadeh · M. Manteghian

Chemical Engineering Faculty, Tarbiat Modares University,

P.O. Box 14155-143, Tehran, Iran

\section{H. Khani ( $\square)$}

Nuclear Fuel Cycle Research School, Nuclear Science and Technology Research Institute, P.O. Box 14395-836, Tehran, Iran

e-mail: mhkhani@aeoi.org.ir electroplating, paints, petrochemical, electronic, and nuclear power plants. Acute cobalt poisoning in humans may cause serious health problems including allergy, vomiting, neurotoxicological symptoms, damage to the heart, thyroid, and liver, whereas chronic exposure can induce partial or complete loss of smell and gastrointestinal troubles (Suhasini et al. 1999; Bhatnagar et al. 2010). It is therefore necessary to remove cobalt at the time of release of effluent. There are some conventional methods for treatment of liquid effluent for removal of heavy metals such as ion exchange, chemical precipitation, reverse osmosis, coagulation, and co-precipitation (Dahiya et al. 2008). Although these conventional techniques can reduce metal ions, they do not appear to be highly effective due to the limitations in the $\mathrm{pH}$ range as well as the high material and operational costs (Ozer et al. 2008). The most popular of these technologies is activated carbon adsorption which is widely used; however, this technique is expensive. Therefore, there is a growing interest in using low-cost, easily available materials for the adsorption of metal ions. A low-cost adsorbent is defined as one which is abundant in nature or is a by-product or waste material from another industry. Biosorbent materials derived from suitable biomass can be used for the effective removal and recovery of heavy metal ions from industrial solutions. Many algae, yeasts, bacteria, and other fungi are known to be capable of concentrating metal species from dilute aqueous solutions and accumulating them within their cell structure (Ozer et al. 2008). Among biosorbent materials, algae have proved to be both economic and eco-friendly, as they are abundantly available, have regeneration and metal recovery potentiality, have high efficiency in dilute effluents, and have high surface-area-to-volume ratio (Pahlavanzadeh et al. 2010). Untreated algae generally contains light metal ions such as $\mathrm{Ca}^{2+}$ and $\mathrm{Mg}^{2+}$ which are originally bound to the acid functional groups of the alga and were acquired from 
seawater (Davis et al. 2003). The basic and important mechanism in biosorption which explains the heavy metal ions uptake is ion exchange due to the electrostatic interactions between the metal cations and anionic carboxyl groups. The carboxylic groups are generally the most abundant acidic functional groups in brown algae (Davis et al. 2003). The adsorption capacity of the algae is directly related to the presence of these sites on the alginate polymer (Kleinubing et al. 2011). Alginic acid or alginate is the common name given to a family of linear polysaccharides containing mannuronic and guluronic acid. Based on the amount of protons released, the affinity of alginic acid to metal ions follows the order $\mathrm{Pb}$ (II) $>\mathrm{Cu}$ (II) $>\mathrm{Cd}$ (II) $>\mathrm{Ba}$ (II) $>\mathrm{Sr}$ (II) $>$ $\mathrm{Ca}$ (II) $>\mathrm{Co}$ (II) $>\mathrm{Ni}$ (II) $>\mathrm{Mn}$ (II) $>\mathrm{Mg}$ (II). The binding strength of alkaline earth metals to both polymannuroate and polyguluronate was found to decrease in the order $\mathrm{Ba}$ (II) $>\mathrm{Sr}$ (II) $>\mathrm{Ca}$ (II) $>\mathrm{Mg}$ (II) (Davis et al. 2003; Kleinubing et al. 2011). Haug (1961) interpreted the preferential binding of heavier ions to stereochemical effects, since larger ions might better fit a binding site with two distant functional groups. Also the preferential binding of larger ions can be attributed to stereochemical effects such as the coordination of the oxygen atoms surrounding the metal ion (papageorgiou et al. 2006). According to the trends, cobalt ion prefers to replace magnesium instead of calcium ion because $\mathrm{Mg}$ (II) has less binding strength. So for pretreatment of biomass, $\mathrm{Mg}$ (II) was used as a surface modifier instead of other ions such as $\mathrm{Ca}$ (II). The mechanism of binding metal ions by inactivated algal biomass may depend on the species and ionic charges of the metal ions, the algal organisms, the chemical compositions of the metal ion solution, and other external environmental factors such as $\mathrm{pH}$ and temperature (Pahlavanzadeh et al. 2010).

Design-Expert software is a program to help optimize the process. This software provides highly efficient design of experiments for factorial designs, response surface methods (RSM), mixture design techniques, and combined designs. Response surface methodology (RSM) is a collection of mathematical and statistical procedures and one approach to evaluate the relative significance of several effective factors by estimating the shape of the response surface and selecting optimum conditions in a limited number of experiments. Second-order models are widely used in RSM to approximate the true response surface. The central composite design (CCD) is the most popular RSM and is used to build second-order models (Omidvar et al. 2014). The results are statistically analyzed by this software. In the statistical methods, the variables involved in an experiment are being simultaneously changed. The most important advantages are that not only the effects of individual parameters but also their relative importance in a given process are evaluated and that the interaction of two or more variables can also be derived. This is not possible in a classical one factor at a time experiment (Demim et al. 2014). Accuracy and precision of experiments are evaluated by the ANOVA results and confirmatory experiment.

The aim of this study was to conduct a central composite design (CCD) analysis for the significant factors that influenced the removal of cobalt from aqueous solution by marine brown algae Sargassum sp. and understand their impact on the process. The effect of some operating variables_chemical modification of the biomass, temperature, $\mathrm{pH}$, adsorbent dose and initial concentration of $\mathrm{Co}^{2+}$, and also their interactions on biosorption was studied using CCD, which gives a mathematical model that shows the influence of each variable and their interactions.

\section{Materials and methods}

\section{Preparation of biosorbents}

Samples of marine algae Sargassum sp. were collected from Persian Gulf on the coast of Qeshm, Iran. Algal samples were washed with tap water and distilled water to remove sand and excess of sodium and potassium ions. After drying overnight at a maximum temperature of $55^{\circ} \mathrm{C}$ to avoid degradation of the binding sites (Diniz et al. 2006), the samples were grounded to an average particle size of $0.7 \mathrm{~mm}$. The biomasses were subsequently loaded with $\mathrm{Mg}^{2+}$ in a solution of $0.1 \mathrm{M} \mathrm{Mg}\left(\mathrm{NO}_{3}\right)_{2} \cdot 6 \mathrm{H}_{2} \mathrm{O}$ (biomass concentration of $10.0 \mathrm{~g} / \mathrm{l}$ ) for $24 \mathrm{~h}$ under slow stirring. Then, pretreated biomass was washed several times with deionized water until a stable wash solution $\mathrm{pH}$ was reached and excess magnesium ions were removed from the biomasses. The Mg-pretreated biomasses were then dried overnight in an oven at $55^{\circ} \mathrm{C}$, and subsequently natural algae and $\mathrm{Mg}$-pretreated algae were used for biosorption experiments.

Preparation of synthetic metal solution

A stock solution of cobalt, with $1,000 \mathrm{ppm}$ concentration, was prepared using $\left(\mathrm{Co}\left(\mathrm{NO}_{3}\right)_{2} \cdot 6 \mathrm{H}_{2} \mathrm{O}\right)$. This solution was diluted depending upon requirements. All solutions were prepared in deionized water. The initial $\mathrm{pH}$ of cobalt solutions was adjusted with diluted or concentrated $\mathrm{HNO}_{3}$ and $\mathrm{NaOH}$ solutions before mixing with the biosorbent. All used chemical materials were of analytical grades (Sigma Aldrich, Germany). 
Characterization test

\section{Scanning electron microscopy}

The surface morphology of the algae was visualized by a scanning electronic microscope VEGA \SEM (TESCAN a.s., Czech Republic). To determine the chemical composition of biosorbent before and after treatment by $0.1 \mathrm{M} \mathrm{Mg}\left(\mathrm{NO}_{3}\right)_{2} \cdot 6 \mathrm{H}_{2} \mathrm{O}$ and also after $\mathrm{Co}^{2+}$ sorption, a system of analysis for energy dispersive X-ray spectroscopy (EDX, RONTECH, Germany) was also used.

\section{Fourier transform infrared spectroscopy}

FTIR spectroscopy was used to detect vibration frequency changes in the brown algae Sargassum sp. before and after pretreatment. The spectra were recorded using FTIR (PerkinElmer Spectrum version 10.03.06, USA) spectrometer within the range of $400-4,000 \mathrm{~cm}^{-1}$ using $\mathrm{KBr}$ pellets.

\section{Analysis of cobalt concentration}

Dissolved cobalt concentrations in solution were assessed by an inductively coupled plasma atomic emission spectrophotometer (ICP-AES, Optima, 7300DV, USA). The ICP analyses were conducted at wavelength of $228.616 \mathrm{~nm}$.

\section{Batch adsorption experiments}

In order to determine the contact time required for the sorption equilibrium experiments, the sorption dynamics experiments were conducted on natural and $\mathrm{Mg}$-pretreated algae first. 0.1 gram of biomass added to a series of $250-\mathrm{ml}$ Erlenmeyer flasks containing $100 \mathrm{ml}$ of $100 \mathrm{mgCo} / \mathrm{l}$ $\mathrm{Co}\left(\mathrm{NO}_{3}\right)_{2} \cdot 6 \mathrm{H}_{2} \mathrm{O}$ solution. The flasks were agitated at $150 \mathrm{rpm}$ and $25^{\circ} \mathrm{C}$ for $24 \mathrm{~h}$ in a shaker. Samples were withdrawn at predetermined time intervals $(2,5,15,30,45$, $60,90,120,150,180$, and 1,440 $\mathrm{min}$ ). These time intervals were selected according to the previous research which has indicated that the absorption rate for most metals is fast initially and the equilibrium time for Cobalt is $<3 \mathrm{~h}$ (Ozdemir et al. 2005; Sun et al. 2008; Dahiya et al. 2008; Maresova et al. 2011; Bulgariu and Bulgariu 2012). After appropriate dilution, the samples were analyzed by the ICP-AES for metal concentrations. According to the preliminary sorption dynamic tests, the equilibrium was reached after 90 min of contact. Batch adsorption experiments were conducted to study the effect of magnesium ion as a surface modifier of biomass, temperature, $\mathrm{pH}$, initial cobalt (II) concentration, and the dosage of biomass. Each experiment was carried out in 250-ml Erlenmeyer flasks containing $100 \mathrm{ml} \mathrm{Co}\left(\mathrm{NO}_{3}\right)_{2} \cdot 6 \mathrm{H}_{2} \mathrm{O}$ solution with known initial cobalt concentration which were mixed to different amount of biomass. The flasks were shaken at $150 \mathrm{rpm}$ for a period contact time of $90 \mathrm{~min}$. The $\mathrm{pH}$ of initial solution was adjusted to the desired values with diluted or concentrated $\mathrm{HNO}_{3}$ and $\mathrm{NaOH}$ solutions before mixing with the biosorbent. Cobalt solution was filtrated through Whatman filter paper. Filtered samples were analyzed for residual cobalt ion concentration. The amount of metal uptake, by algae, was calculated from the differences between the metal quantity added to the biomass and the metal content of the supernatant using the following equation:

$q=\frac{V\left(C_{0}-C\right)}{M_{\mathrm{ads}}}$

where $q$ is the amount of metal ions adsorbed on the biosorbent at any time, $t$, in $\mathrm{mg} / \mathrm{g}, V$ is the volume of metal containing solution in contact with the biosorbent in $\mathrm{ml}, C_{0}$ is the initial concentration of metal in $\mathrm{mg} / \mathrm{l}, C$ is the metal concentration in the solution at any time $t(\mathrm{~min})$ in $\mathrm{mg} / \mathrm{l}$, and $M_{\text {ads }}$ is the amount of added biosorbent on dry basis in g (Khani 2011).

\section{Experimentation and optimization of biosorption}

In the study, the effects of operating parameters were optimized using response surface methodology (RSM). RSM is essentially a particular set of mathematical and statistical methods for designing experiments, building and validating the models, evaluating the effects of variables, estimating interaction between variables, and searching optimum conditions of variables to predict targeted responses (Ozer et al. 2008; Khodadoust et al. 2014). The application of statistical experimental design techniques in sorption processes could result in improved product yields, reduced process variability, as well as reduced development time and overall costs (Annadurai et al. 2003).

In the study, central composite design (CCD) was used for the RSM in the experimental design, which is well suited for fitting a quadratic surface and usually works well for the process optimization (Ozer et al. 2008). The CCD consisted of a $2^{k}$ factorial runs with $2 k$ axial runs and $r$ center runs. The center points were used to evaluate the experimental error and the reproducibility of the data. The independent variables were coded to the $(-1,1)$ interval where the low and high levels were coded as -1 and +1 , respectively. The axial points were located at $( \pm \alpha, 0,0),(0$, $\pm \alpha, 0)$, and $(0,0, \pm \alpha)$. In this study, $\alpha$ was fixed 2.0 which is the default setting of software for up to five factors that makes the design Rotatable; this creates a design that has the standard error of predictions equal at points equidistant from the center of the design. 
Therefore, central composite design with four numeric factors (initial cobalt (II) concentration: $50-300 \mathrm{mg} / \mathrm{l}$, biosorbent dosage: $0.1-0.5 \mathrm{~g}$, initial $\mathrm{pH}$ : $2.5-7.0$ and temperature: $15-45^{\circ} \mathrm{C}$ ) and one categorical factor at two levels (natural Sargassum sp. and Mg- pretreated Sargassum sp. algae) was applied using Design-Expert software version 7 (Stat-Ease Inc., Minneapolis, USA) as shown in Table 1. Performance of the process was evaluated by analyzing the response of biosorbent for cobalt (II) ions. The responses were biosorption capacity of natural and modified algae, $y_{1}$ and $y_{2}$, respectively.

In the optimization process, the responses can be simply related to chosen factors by linear or quadratic models. A quadratic model, which also includes the linear model, is given as;

$y=b_{0}+\sum_{i=1}^{k} b_{i} x_{i}+\sum_{i=1}^{k} b_{i i} x_{i}^{2}+\sum_{i=1}^{k} \sum_{j=1}^{k} b_{i j} x_{i} x_{j}$

where $b_{0}, b_{i}, b_{i i}, b_{i j}$ are a constant, a linear coefficient, a square coefficient, and an interaction coefficient, respectively (Ozer et al. 2008; Mafi Gholami et al. 2012; Khodadoust et al. 2014).

In this work, a central composite design was used to estimate the effect of five independent factors (temperature, $x_{1}$; initial concentration of cobalt (II), $x_{2}$; biosorbent dosage, $x_{3}$; initial $\mathrm{pH}, x_{4}$; and natural brown algae and $\mathrm{Mg}$ pretreated brown algae, $x_{5}$ ) on the biosorption capacities $\left(y_{1}, y_{2}\right)$ as the responses were processed for Eq. (2) including analysis of variance (ANOVA) to obtain the interaction between the process variables and the responses. Analysis of variance (ANOVA) of proposed results is undertaken to identify the individual and interactive effect of all variables. The validated model can be plotted in tridimensional graph to generate a surface response corresponding to a response function that admit to determine the best operating conditions of the process (Roosta et al. 2014). The coefficients of determination, $R^{2}$ and $R_{\mathrm{adj}}^{2}$, expressed the quality of the fit of polynomial model. The statistical significance was checked with adequate precision ratio and $F$ test (Ozer et al. 2008). The second-order polynomial models were represented as response, while keeping constant third variable (Freitas et al. 2009).

\section{Results and discussion}

Statistical analysis

In order to determine the significant factors and the interaction between them, 56 experimental runs were statistically analyzed with CCD design. $P$ value was used as a tool to check the significance of every coefficient. The smaller the magnitude of $P$, the more significant is the corresponding coefficient. $P$ values $<0.05$ indicate that model parameters are significant. In our experiment, all five factors and $\mathrm{AB}\left(T, C_{0}\right), \mathrm{BC}\left(C_{0}, M_{\mathrm{ads}}\right), \mathrm{BD}\left(C_{0}, \mathrm{pH}\right)$, and $\mathrm{BE}$ $\left(C_{0}\right.$, Type of biosorbent) interactions are highly significant $(P<0.05)$. ANOVA results after eliminating the insignificant parameters for the reduced quadratic model are summarized in Table 2. The final responses for the biosorption capacity of untreated and treated biomasses for cobalt (II) ions were obtained in Eqs. (3) and (4), respectively.

$$
\begin{aligned}
y_{1}= & 27.01193-0.039876 x_{1}+0.21785 x_{2} \\
& -109.62840 x_{3}+2.06483 x_{4} \\
& +9.15733 E-004 x_{1} x_{2}-0.13322 x_{2} x_{3}+0.010372 x_{2} x_{4} \\
& -3.85354 E-004 x_{2}^{2}+98.69344 x_{3}^{2}-0.35106 x_{4}^{2} \\
y_{2}= & 26.75589-0.039876 x_{1}+0.24190 x_{2} \\
& -109.62840 x_{3}+2.06483 x_{4} \\
& +9.15733 E-004 x_{1} x_{2}-0.13322 x_{2} x_{3}+0.010372 x_{2} x_{4} \\
& -3.85354 E-004 x_{2}^{2}+98.69344 x_{3}^{2}-0.35106 x_{4}^{2}
\end{aligned}
$$

Nonsignificant lack of fit $P$ value shows the validity of the quadratic model for biosorption by Sargassum sp. biomass. The obtained values for the correlation between the actual and predicted response $\left(R^{2}\right)$ and coefficient adjusted $R^{2}$ are 0.9908 and 0.9883 , respectively. These

Table 1 Experimental range and levels of the control factors in the CCD

\begin{tabular}{llllll}
\hline Variable & $C_{0}(\mathrm{mg} / \mathrm{g})$ low axial $(-\alpha)^{\mathrm{a}}$ & Low factorial $(-1)$ & Center & High factorial $(+1)$ & High axial $(+\alpha)^{\mathrm{a}}$ \\
\hline$M_{\text {ads }}(\mathrm{g}) x_{1}(A):$ Temperature $\left({ }^{\circ} \mathrm{C}\right)$ & 15 & 23 & 30 & 38 & 45 \\
$x_{2}(B):$ Initial cobalt $(\mathrm{II})$ concentration $(\mathrm{mg} / \mathrm{l})$ & 50 & 113 & 175 & 238 & 300 \\
$x_{3}(C):$ Biosorbent dosage $(\mathrm{g})$ & 0.1 & 0.2 & 0.3 & 0.4 & 0.5 \\
$x_{4}(D): \mathrm{pH}$ & 2.5 & 3.6 & 4.8 & 5.9 & 7 \\
& Level 1 & & Level 2 & Mg- pretreated Sargassum sp. \\
$x_{5}(\mathrm{E}):$ Type of biosorbent & natural Sargassum $\mathrm{sp}$. & & & \\
\hline
\end{tabular}

a $\alpha=2$ 
Table 2 ANOVA for the response surface-reduced quadratic model for cobalt biosorption

\begin{tabular}{|c|c|c|c|c|c|}
\hline Source & Sum of squares & Df & Mean square & $F$ value & $P$ value \\
\hline Model & $6,424.25$ & 12 & 535.35 & 386.89 & $<0.0001$ \\
\hline$A-T$ & 39.13 & 1 & 39.13 & 28.28 & $<0.0001$ \\
\hline$B-C_{0}$ & $3,255.71$ & 1 & $3,255.71$ & $2,352.86$ & $<0.0001$ \\
\hline $\mathrm{C}-M_{\mathrm{ads}}$ & $2,609.04$ & 1 & $2,609.04$ & $1,885.52$ & $<0.0001$ \\
\hline$D-\mathrm{pH}$ & 18.03 & 1 & 18.03 & 13.03 & 0.0008 \\
\hline$E-E$ & 218.63 & 1 & 218.63 & 158.00 & $<0.0001$ \\
\hline $\mathrm{AB}$ & 5.90 & 1 & 5.90 & 4.26 & 0.0451 \\
\hline $\mathrm{BC}$ & 22.18 & 1 & 22.18 & 16.03 & 0.0002 \\
\hline $\mathrm{BD}$ & 17.02 & 1 & 17.02 & 12.30 & 0.0011 \\
\hline $\mathrm{BE}$ & 27.10 & 1 & 27.10 & 19.59 & $<0.0001$ \\
\hline $\mathrm{B}^{2}$ & 116.01 & 1 & 116.01 & 83.84 & $<0.0001$ \\
\hline$C^{2}$ & 49.87 & 1 & 49.87 & 36.04 & $<0.0001$ \\
\hline$D^{2}$ & 10.11 & 1 & 10.11 & 7.30 & 0.0098 \\
\hline Residual & 59.50 & 43 & 1.38 & & \\
\hline Lack of fit & 52.89 & 37 & 1.43 & 1.30 & 0.4017 \\
\hline Pure error & 6.61 & 6 & 1.10 & & \\
\hline Cor total & $6,483.75$ & 55 & & & \\
\hline
\end{tabular}

values are in reasonable agreement for cobalt (II) which is closer to 1.0 , indicating the better fitness of the reduced quadratic model in the experimental data. Adequate precision value is the "signal-to-noise ratio", and a ratio $>4$ is desirable. The ratio of 77.361 indicates an adequate signal. This model can be used to navigate the design space. The coefficient of variance $(\mathrm{CV})$ value was found to be 3.13 for biosorption capacity. Since $\mathrm{CV}$ is a measure expressing standard deviation as a percentage of the mean, the small values of $\mathrm{CV}$ give better reproducibility. In general, a CV higher than ten indicates that variation in the mean value is high and does not satisfactorily develop an adequate response model (Ozer et al. 2008).

The predicted values calculated from the statistical model versus the actual response values obtained by the experiment are shown in Fig. 1a. It approves the suitability of the model since all the points are located around the diagonal line. The normal probability and studentized residuals plot are shown in Fig. 1b for the biosorption capacity of Sargassum sp. for cobalt (II) ions. In Fig. 1b, residuals show how well the model satisfies the assumptions of the analysis of variance (ANOVA) where the studentized residuals measure the number of standard deviations separating the actual and predicted values. Figure $1 \mathrm{~b}$ shows that neither response transformation needed nor there was apparent problem with normality.

\section{Statistical optimization}

The aim of the process was to maximize biosorption capacity of biosorbent for cobalt (II) ions and find optimized conditions. The optimum values for temperature, initial cobalt (II) concentration, biosorbent dosage, and $\mathrm{pH}$ were estimated to be $45^{\circ} \mathrm{C}, 300 \mathrm{mg} / \mathrm{l}$, $0.1 \mathrm{~g}$, and 7.0, respectively. According to the optimum conditions, the best biosorbent which had the maximum metal uptake $(80 \mathrm{mg} / \mathrm{g})$ was $\mathrm{Mg}\left(\mathrm{NO}_{3}\right)_{2} \cdot 6 \mathrm{H}_{2} \mathrm{O}$-treated biomass (Mg-treated biomass). The software calculated the expected responses and associated confidence intervals based on the prediction equations (Eqs. (3), (4)). The $95 \%$ confidence interval (C.I.) is the range in which the process average was expected to fall $95 \%$ of the time, while the $95 \%$ prediction interval (P.I.) is the range in which it was expected that any individual value to fall $95 \%$ of the time (Mafi Gholami et al. 2012). As shown in Table 3, the P.I. is larger (a wider spread) than the C.I. since more scatter in individual values is expected than in averages. In this table, SE mean refers to the standard deviation associated with the prediction of an average value at the selected component levels, while the standard deviation associated with SEpred. indicates the prediction of an individual observation at the selected factor levels.

Table 3 Point prediction of the responses at the optimal conditions

\begin{tabular}{llllllll}
\hline Response & Prediction & SE mean & $95 \%$ C.I. low & $95 \%$ C.I. high & SE pred. & $95 \%$ P.I. low & $95 \%$ P.I. high \\
\hline$q(\mathrm{mg} / \mathrm{g})$ & 80.21 & 1.94 & 76.29 & 84.13 & 2.27 & 75.63 & 84.79 \\
\hline
\end{tabular}



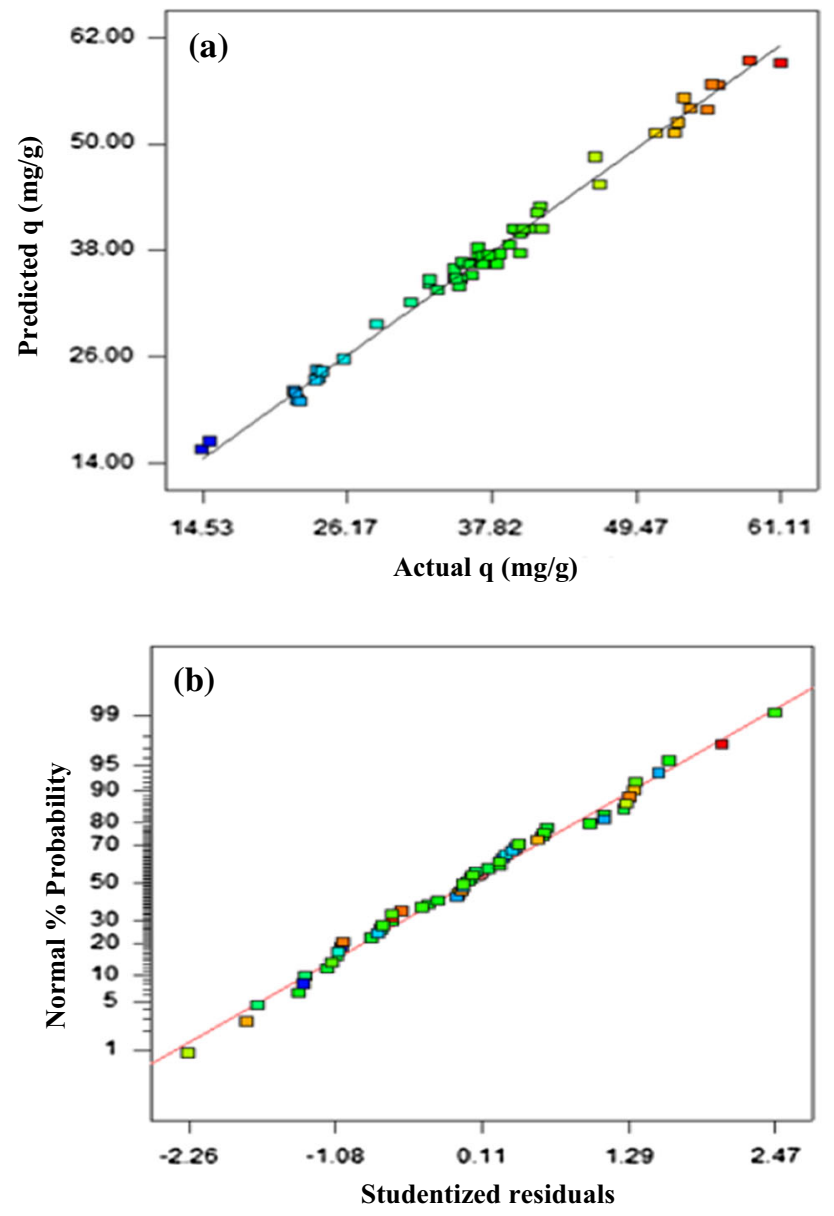

Fig. 1 a Scatter graph of the predicted response values versus the actual response values for the biosorption capacity of biomass for cobalt. b Normal plot of studentized residuals verses normal \% probability for bearing the experiment for cobalt ions

Effect of pretreatment on biosorption capacity and sorption mechanism

The chemically modified biosorbent increases the stability of the biosorbent material and enhances the biosorbent properties (Khani et al. 2006). The interactive effect of initial cobalt (II) concentration and type of biomass on the cobalt uptake of biomass holding other variables at their central values is shown in Fig. 2. The capacities of treated and untreated Sargassum sp. for cobalt ion at different concentrations indicated that the treatment of $\mathrm{Mg}\left(\mathrm{NO}_{3}\right)_{2}$ had enhanced the adsorption capacity. The adsorption capacity for untreated Sargassum sp. and treated Sargassum sp. increased from 15.43 to $45.49 \mathrm{mg} / \mathrm{g}$ and $16.37-52.45 \mathrm{mg} / \mathrm{g}$, respectively, with the increase in the initial concentration of cobalt from 50 to $300 \mathrm{mg} / \mathrm{l}$. According to the Table 2, the interaction between initial cobalt (II) concentration and type of biomass (BE) was highly significant $(P<0.0001)$. Samples of biomasses

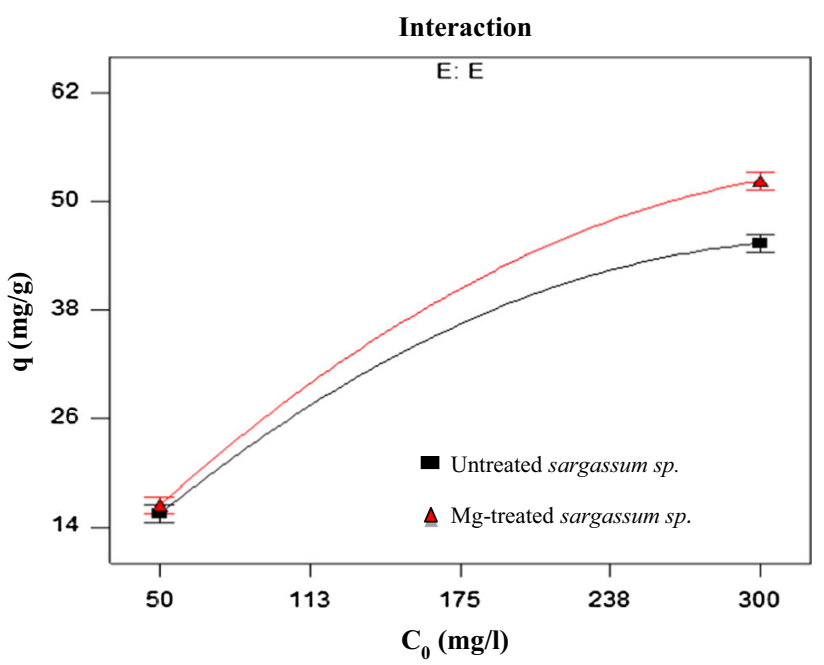

Fig. 2 Intraction plot showing effect of initial cobalt (II) concentration and type of biomass on the cobalt uptake of biomass holding other variables at their central values

before and after metal adsorption were observed using the SEM/EDS technique with the aim of identifying the surface microstructures and determining the chemical composition. Figure 3a shows the approximate dimensions of the natural Sargassum sp; the morphology of surface of Mg-treated algae is displayed in Fig. 3b. The biomass surface after sorption of Co (II) is shown in Fig. 3c. Element mapping clearly demonstrated a uniform distribution of Co (II) onto biosorbent surface (Fig. 3d). Also EDX spectra taken in spot profile mode show the enhancement of magnesium peaks on EDX spectra of biomass after treatment comparing with biosorbent before $\mathrm{Mg}$ treatment (Fig. 4a, b) and also confirm presence of cobalt (Fig. 4c), suggesting bonding of metal cations onto algae surface by interactions with negatively charged functional groups. Additionally, for the samples after biosorption, we observed that the peaks of Mg on EDX spectra of biosorbent after metal sorption were omitted (Fig. 4c). The amount of magnesium and cobalt of the untreated Sargassum sp., Mg-treated biomass, and cobalt-loaded biomass was determined using an EDX spectrometer, as shown in Table 4. Our findings suggest that $\mathrm{Co}^{2+}$ ions have replaced $\mathrm{Mg}^{2+}$ ions from biosorbent surface and ion exchange mechanism participates in cobalt biosorption. The same conclusions were also postulated by others (Vijayaraghavan et al. 2005; Bishnoi et al. 2007). However, due to the complexity of biomaterials, other mechanisms such as coordination and chelation of metals, adsorption, and surface complexation of cations with exposed functional groups on the biomass might be acting simultaneously, to varying degrees, depending on the biosorbent and the solution chemistry (Suhasini et al. 1999; Sheng et al. 2004; Maresova et al. 2011). 
(a)

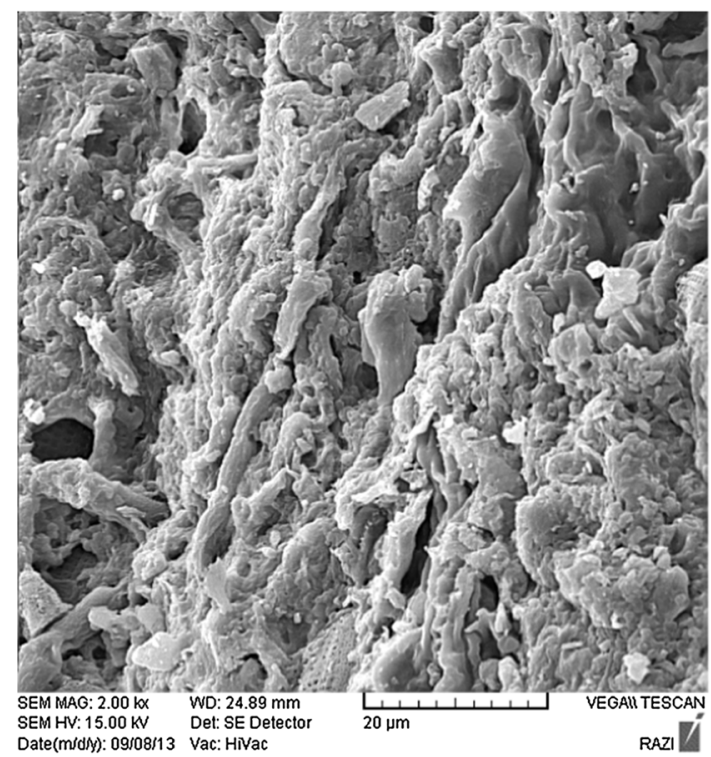

(c)

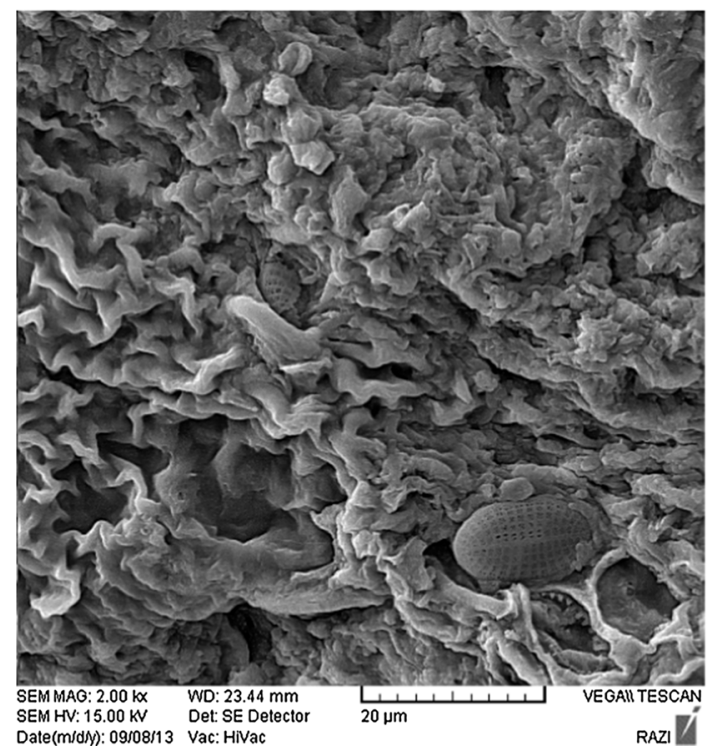

(b)

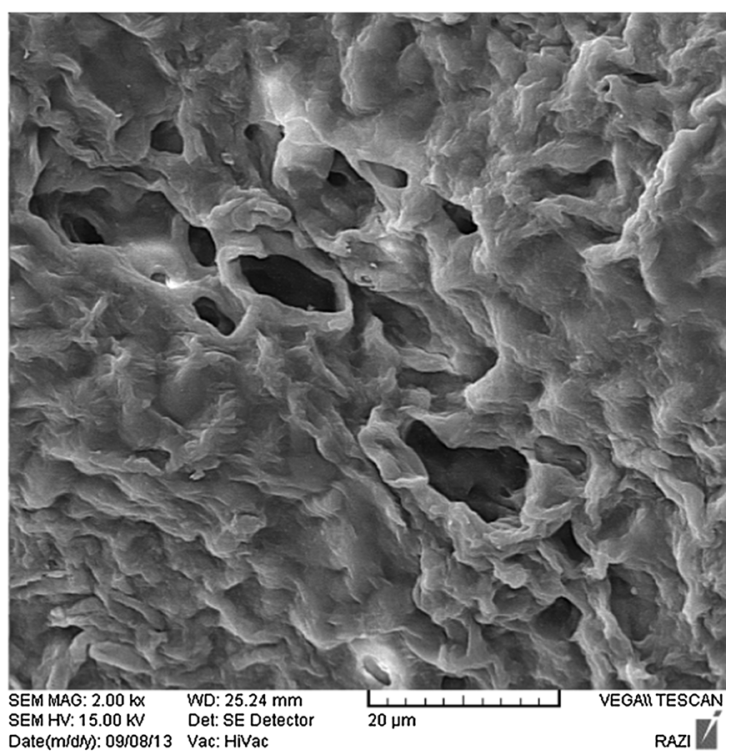

(d)

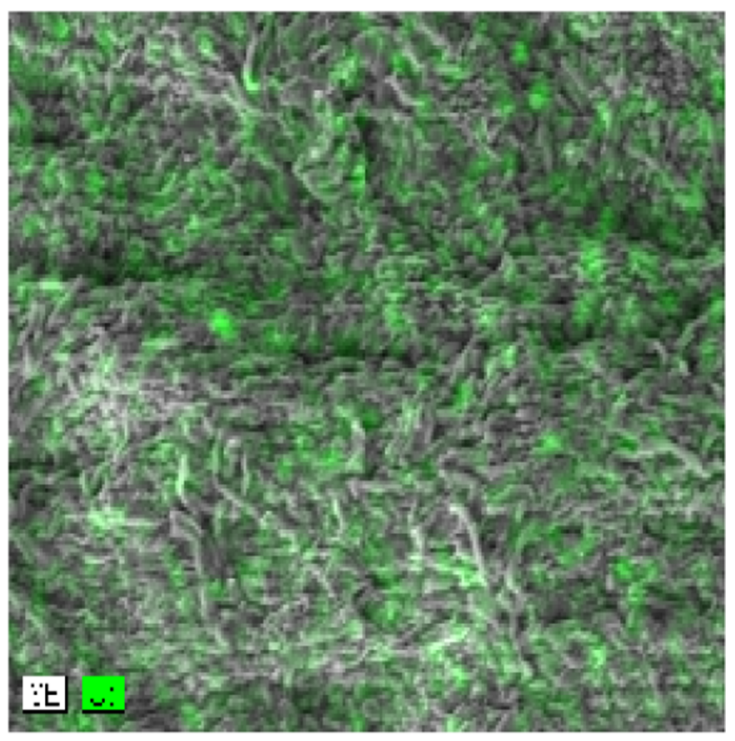

Fig. 3 SEM micrographs of biomass: a natural biomass; b Mg-treated Sargassum sp.; c Co-loaded Sargassum sp.; and d Element mapping of the surface of biomass after cobalt sorption

The FTIR spectra of the natural Mg-treated and cobaltloaded brown marine algae Sargassum sp. are shown in Fig. 5a, b, and c. The FTIR spectroscopic analysis indicated broad bands at $3,418 \mathrm{~cm}^{-1}$, representing carboxylic bonded $-\mathrm{OH}$. For the pristine Sargassum sp. biosorbent, it was clear that the carboxylate ions gave rise to two bands: a strong asymmetrical stretching band at $1,645 \mathrm{~cm}^{-1}$ and a weaker symmetrical stretching band at $1,423 \mathrm{~cm}^{-1}$. The double bands of the carboxylate ion are representative of the alginate-based polymer which is present in Sargassum sp. (Chen et al. 2002; Sheng et al. 2004). Both bands exhibited shifts to different extents after contact with metal solutions. The peak values suggested the chelating (bidentate) character of the metal biosorption onto carboxyl groups (Figueira et al. 1999; Sheng et al. 2004).The structure of the metal bound to carboxyl ligands on the brown algae is expected to have the following form (Figueira et al. 1999; Sheng et al. 2004):<smiles>[R]c1[M]oc1</smiles> 
Fig. 4 EDX analysis of Sargassum sp. before a and after b $\mathrm{Mg}$ treatment and after c cobalt (II) sorption. Au peak comes from sample coating
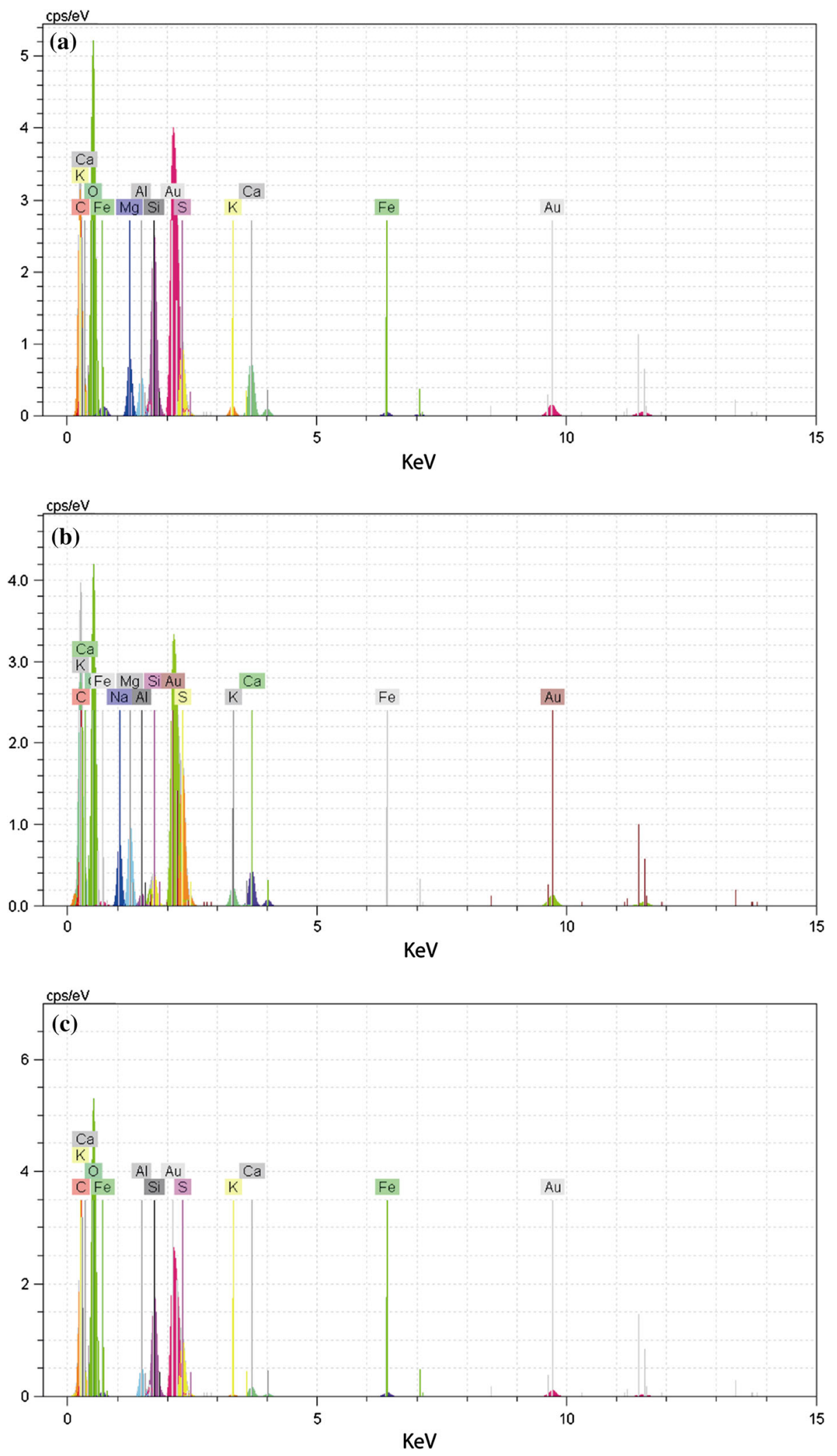

It was possible to identify two absorbance peak shifts in the FTIR spectra which are characteristic of coordination compounds between carboxyl groups and the cations used. The distance between these two peaks $(\Delta)$ is related to the relative symmetry of the carboxyl group and reflects the nature of the coordination compound. 
The FTIR spectra suggest the chelating character of the metal biosorption onto carboxyl groups (Figueira et al. 1999).

Table 4 Amount of magnesium and cobalt of the biomass

\begin{tabular}{llr}
\hline Type of biomass & \multicolumn{2}{l}{ Element (wt $)$} \\
\cline { 2 - 3 } & Magnesium & Cobalt \\
\hline Untreated Sargassum sp. & 1.91 & 0.00 \\
Mg-treated Sargassum sp. & 4.19 & 0.00 \\
Cobalt-loaded Sargassum sp. & 0.00 & 11.04 \\
\hline
\end{tabular}

Some structural characteristics of untreated Sargassum sp. and Mg-treated Sargassum sp. are presented in Table 5. The pretreatment process led to increase in density from 1.36 to $1.47 \mathrm{~g} / \mathrm{cm}^{3}$ and BET surface area decrease from to 13.39 to $11.64 \mathrm{~m}^{2} / \mathrm{g}$. The results indicated that the chemical pretreatment changes the cell wall structure of biomass.

Value of the adsorption capacity of Sargassum sp. adsorbent from the present study was compared with other adsorbents reported in previous studies for cobalt removal and is compiled in Table 6. It is evident from this table that
Fig. 5 FTIR spectra of the biomass: a natural biomass; b Mg-treated Sargassum sp.; and c Co-loaded Sargassum sp
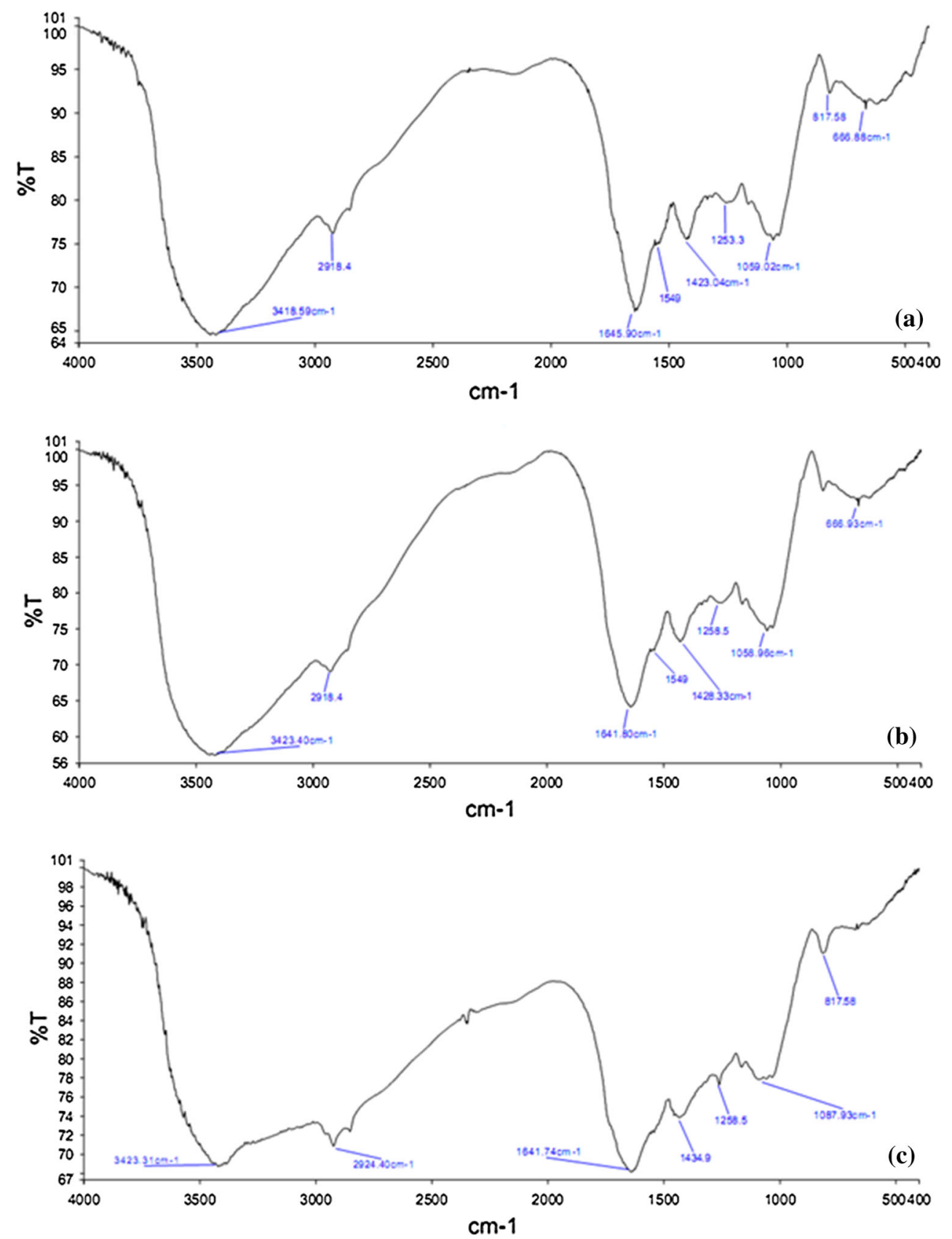
Table 5 Structural properties of untreated and Mg-treated Sargassum sp

\begin{tabular}{lll}
\hline Property & $\begin{array}{l}\text { Untreated } \\
\text { Sargassum } \mathrm{sp} .\end{array}$ & $\begin{array}{l}\text { Mg-treated } \\
\text { Sargassum } \mathrm{sp} .\end{array}$ \\
\hline Density $\left(\mathrm{g} / \mathrm{cm}^{3}\right)$ & 1.36 & 1.47 \\
Pore volume $\left(\mathrm{cm}^{3} / \mathrm{g}^{1}\right)$ & $2.30 \mathrm{E}-2$ & $1.78 \mathrm{E}-2$ \\
Pore size $(\mathrm{nm})$ & 6.87 & 6.11 \\
Porosity $(\%)$ & 3.11 & 2.62 \\
BET surface area $\left(\mathrm{m}^{2} / \mathrm{g}^{1}\right)$ & 13.39 & 11.64 \\
\hline
\end{tabular}

the adsorption capacity of Mg-treated Sargassum sp. for Co (II) is comparable with the other adsorbents.

Effect of operating parameters on biosorption

As shown in Table 2, the results indicated that all linear and quadratic parameters and mutual interaction between temperature and initial cobalt (II) concentration (AB), initial cobalt (II) concentration and biomass dosage (BC), and initial cobalt (II) concentration and $\mathrm{pH}$ (BD) were significant $(P<0.0001, P<0.05)$. The response surface plots (three-dimensional graphs and contour plots) presented in Figs. 4, 5, 6 were generated by varying two factors while keeping the others constant in center values.

Adsorption solution $\mathrm{pH}$ influences both cell surface metal binding sites and metal chemistry in water (Diniz 2006). These phenomena presumably are due to its influence on the surface properties of the adsorbent and ionization/dissociation of the adsorbate molecule (Ghaedi et al. 2014a). Cobalt predominantly exists as $\mathrm{Co}^{2+}$ cation within broad $\mathrm{pH}$ range from 2.5 to 7.0. The precipitation of cobalt (formation of $\mathrm{Co}(\mathrm{OH})_{2}$ form) starts at $\mathrm{pH} 7.5$, and therefore, the $\mathrm{pH}$ range studied was between 2.5 and 7.0. $\mathrm{pH}$ values above seven were not studied because cobalt removal by hydroxide formation begins to interfere with cobalt removal by biosorption and it will be difficult to distinguish between cobalt biosorption and precipitation (Suhasini et al. 1999; Dahiya et al. 2008; Li et al. 2008; Sun et al. 2008; Maresova et al. 2011). Figure 6 shows the effects of initial cobalt (II) concentration and $\mathrm{pH}$ (BD) on the biosorption capacity for Mg-treated biomass. Cobalt uptake significantly increases with metal concentration but a smaller rise with $\mathrm{pH}$ is observed. According to the Fig. 6, the biosorption capacity at $\mathrm{pH} 7.0$ and $\mathrm{pH} 2.5$ was 54.73 and $46.44 \mathrm{mg} / \mathrm{g}$, respectively, and the $\mathrm{Co}^{2+}$ concentration was $300 \mathrm{mg} / \mathrm{l}$ while the other parameters are in the center values $\left(T=30{ }^{\circ} \mathrm{C}\right.$ and $\left.M_{\text {ads }}=0.3 \mathrm{~g}\right)$. Our findings show that the biosorption uptake did not vary significantly with initial $\mathrm{pH}$, indicating that the biosorbent can be used with comparable effectiveness in the $\mathrm{pH}$ range 2.5-7.0. At the algal particles surface, the biosorption capacity decreases with decreasing $\mathrm{pH}$, due to competition of proton with metal ions for binding to the same sorbent sites (Ghaedi et al. 2013b). Oppositely, at higher $\mathrm{pH}$, where cobalt concentration is much greater than $\mathrm{H}^{+}$concentration, the metal uptake increases. Similar results have been obtained by other authors (Suhasini et al. 1999; Vijayaraghavan et al. 2005; Ozdemir et al. 2005; Freitas et al. 2009; Maresova et al. 2011) that found an optimal $\mathrm{pH}$ range of 4-7. At this $\mathrm{pH}$ range, some functional groups in the algae surface, e.g., carboxyl and sulfate, become negatively charged, increasing the electrostatic interactions with the metal cation (Freitas et al. 2009).

The biosorption is highly dependent on the amount of metal initially present in solution, increasing with the initial concentration. For example, the biosorption capacity changes about $+41.79 \mathrm{mg} / \mathrm{g}$ by increasing initial $\mathrm{Co}^{2+}$

Table 6 Comparison of adsorption capacity of various adsorbents for cobalt removal

\begin{tabular}{|c|c|c|c|c|c|c|}
\hline \multirow[t]{2}{*}{ Biosorbent type } & \multirow[t]{2}{*}{ Biosorption capacity (mg/g) } & \multicolumn{4}{|c|}{ Operation condition } & \multirow[t]{2}{*}{ Reference } \\
\hline & & $\mathrm{pH}$ opt & $\begin{array}{l}\text { Biomass } \\
(\mathrm{g} / \mathrm{l})\end{array}$ & $\begin{array}{l}C_{0} \\
(\mathrm{mg} / \mathrm{l})\end{array}$ & $\mathrm{T}\left({ }^{\circ} \mathrm{C}\right)$ & \\
\hline PFB1 (fungi) & 190.00 & 7.0 & 2.00 & - & 30 & Suhasini et al. (1999) \\
\hline Chryseomonas luteola TEM05 (bacteria) & 45.50 & 6.0 & 1.00 & 150 & 25 & Ozdemir et al. (2005) \\
\hline Sargassum wightii & 20.63 & 4.5 & 2.00 & 100 & 25 & Vijayaraghavan et al. (2005) \\
\hline Arca shell & 7.82 & 4.0 & 12.50 & 100 & 25 & Dahiya et al. (2008) \\
\hline Aerobic granules & 52.40 & 5.0 & 1.00 & 300 & 20 & Sun et al. (2008) \\
\hline Almond green hull & 45.50 & - & 0.25 & - & 25 & Ahmadpour et al. (2009) \\
\hline Lemon peel & 22.00 & 6.0 & 10.00 & - & 25 & Bhatnagar et al. (2010) \\
\hline Rhytidiadelphus squarrosus (moss) & 7.26 & 6.0 & 2.50 & - & 20 & Maresova et al. (2011) \\
\hline Green algae & 43.07 & 5.0 & 8.00 & 36.58 & 10 & Bulgariu and Bulgariu (2012) \\
\hline Mg-treated Sargassum sp. & 80.55 & 7.0 & 1.00 & 300 & 45 & This study \\
\hline
\end{tabular}



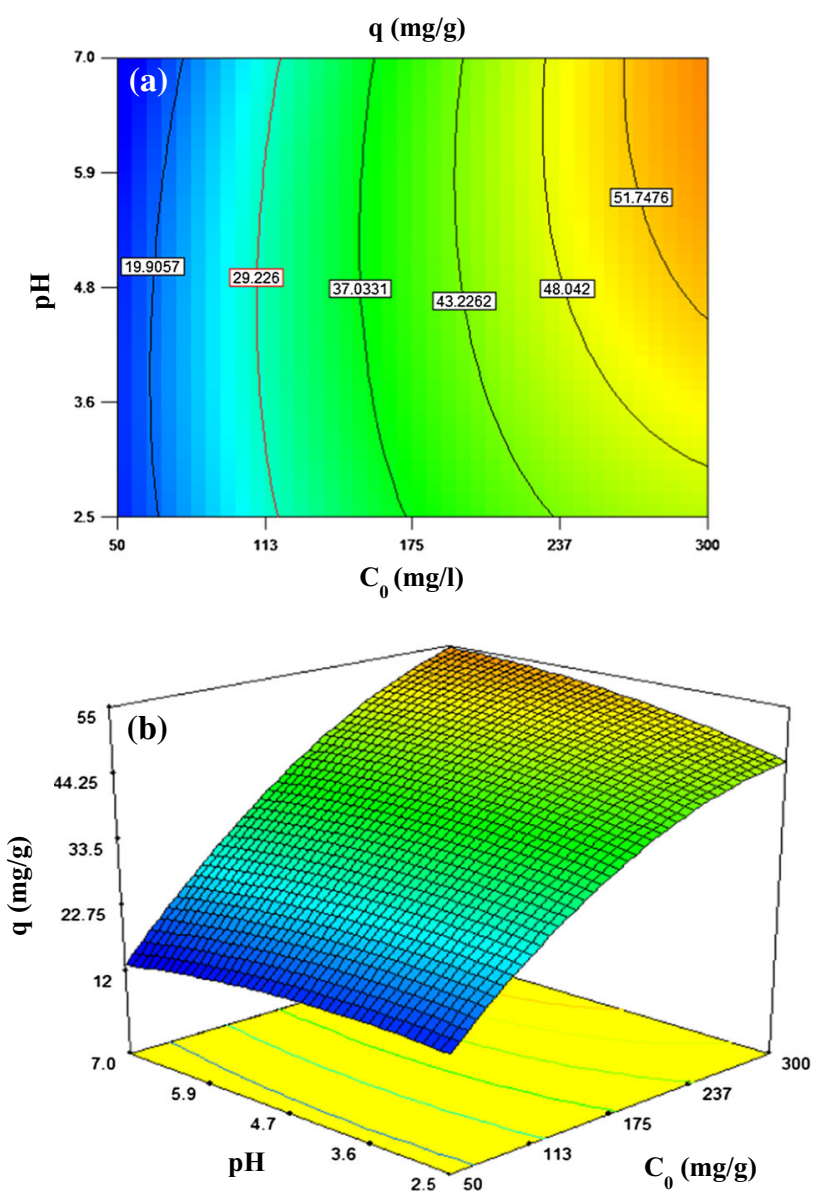

Fig. 6 Three-dimentional plots showing effects of initial cobalt (II) concentration and $\mathrm{pH}(\mathrm{BD})$ on the biosorption capacity for Mg-treated biomass holding other variables at their central values

concentration from 50 to $300 \mathrm{mg} / \mathrm{l}$ at $\mathrm{pH}$ 7. At higher concentrations of cobalt ions in the solution, the active sites of Sargassum sp. are surrounded by more cobalt ions and biosorption is carried out more sufficiently. Similar results are also reported by researchers for a variety of adsorbateadsorbent systems (Dahiya et al. 2008; Khani et al. 2008; Ahmadpour et al. 2009). The rise of metal uptake by increasing initial metal ion concentration is as a result of the driving force of the concentration gradient, rather than the initial metal ion concentration (Ghorbani et al. 2008). The initial concentration provides an important driving force to overcome all mass transfer resistance of cobalt between the aqueous and solid phases.

The interactive effect of temperature and initial cobalt (II) concentration $(\mathrm{AB})$ on the cobalt uptake of Mg-treated biomass holding other variables at their central values is shown in Fig. 7. The biosorption capacity of treated Sargassum sp. increased with the rise in biosorption temperature and initial cobalt (II) concentration. The maximum biosorption capacity occurred at $45^{\circ} \mathrm{C}$. However, temperature variation between 15 and $45{ }^{\circ} \mathrm{C}$ slightly increases the
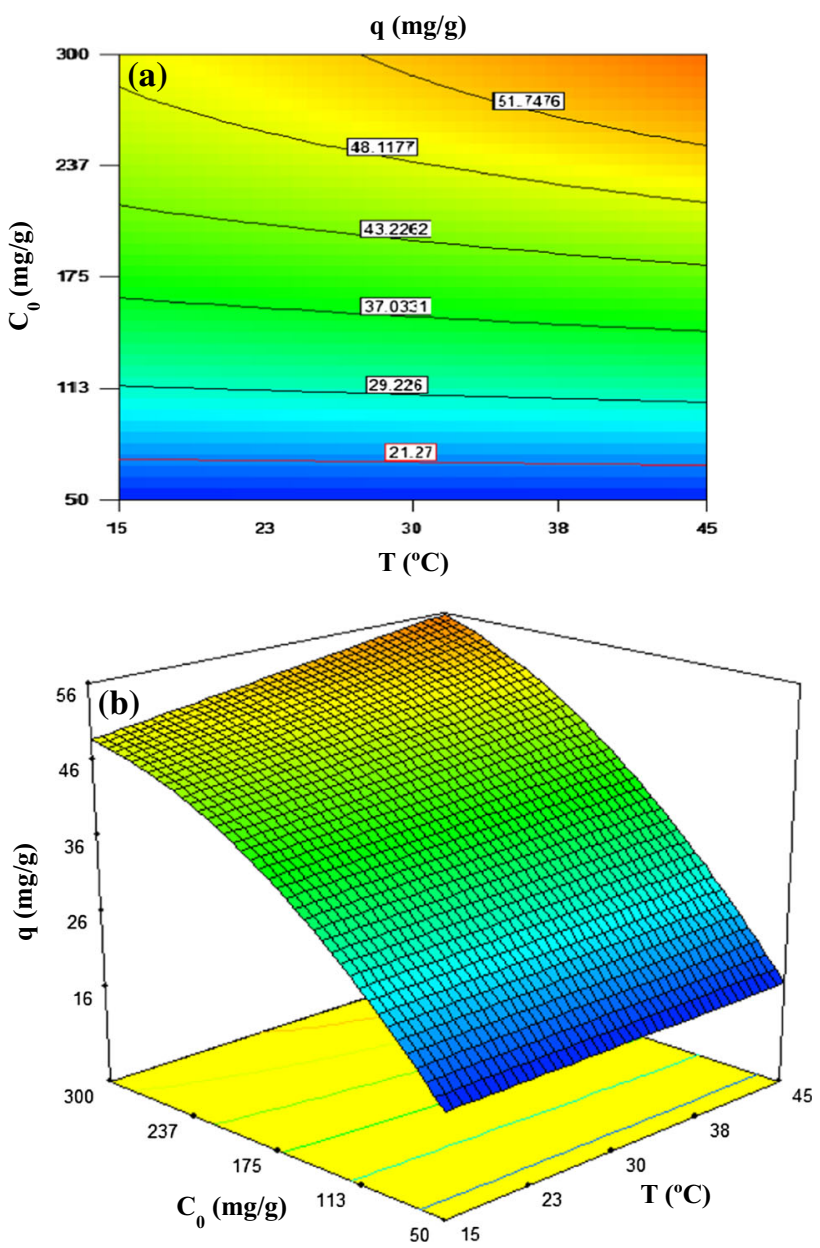

Fig. 7 Three-dimensional plots showing effects of temperature and initial cobalt (II) concentration (AB) on the cobalt uptake of $\mathrm{Mg}$ treated biomass holding other variables at their central values

metal uptake capacity from 38.63 to $42.24 \mathrm{mg} / \mathrm{g}$, respectively. The uptake capacity was calculated at $\mathrm{pH} 4.8$, $175 \mathrm{mg} / \mathrm{l}$ initial cobalt (II) concentration and $0.3 \mathrm{~g}$ biomass dosage. These results indicate the negligible interaction effect of these two parameters on biosorption capacity which is confirmed by the result of ANOVA as shown in Table $2(P$ value $=0.0451)$. Increased biosorption of heavy metals with increasing temperature has been ascribed to cause rupture that possibly enhances the number of active sites involved in metal sorption or the affinity of sites for metal ions, respectively (Freitas et al. 2009). However, the temperature effect seems to be contradictory, as reported by several authors: It can increase (Tsezos et al. 1981; Kuyucak et al. 1989), decrease (Khani et al. 2008; Khani 2011; Bulgariu and Bulgariu 2012; Ghaedi et al. 2013a), or keep the algae ability for metal sorption unaffected (Deng et al. 2006; Freitas et al. 2009; Ahmadpour et al. 2009). 

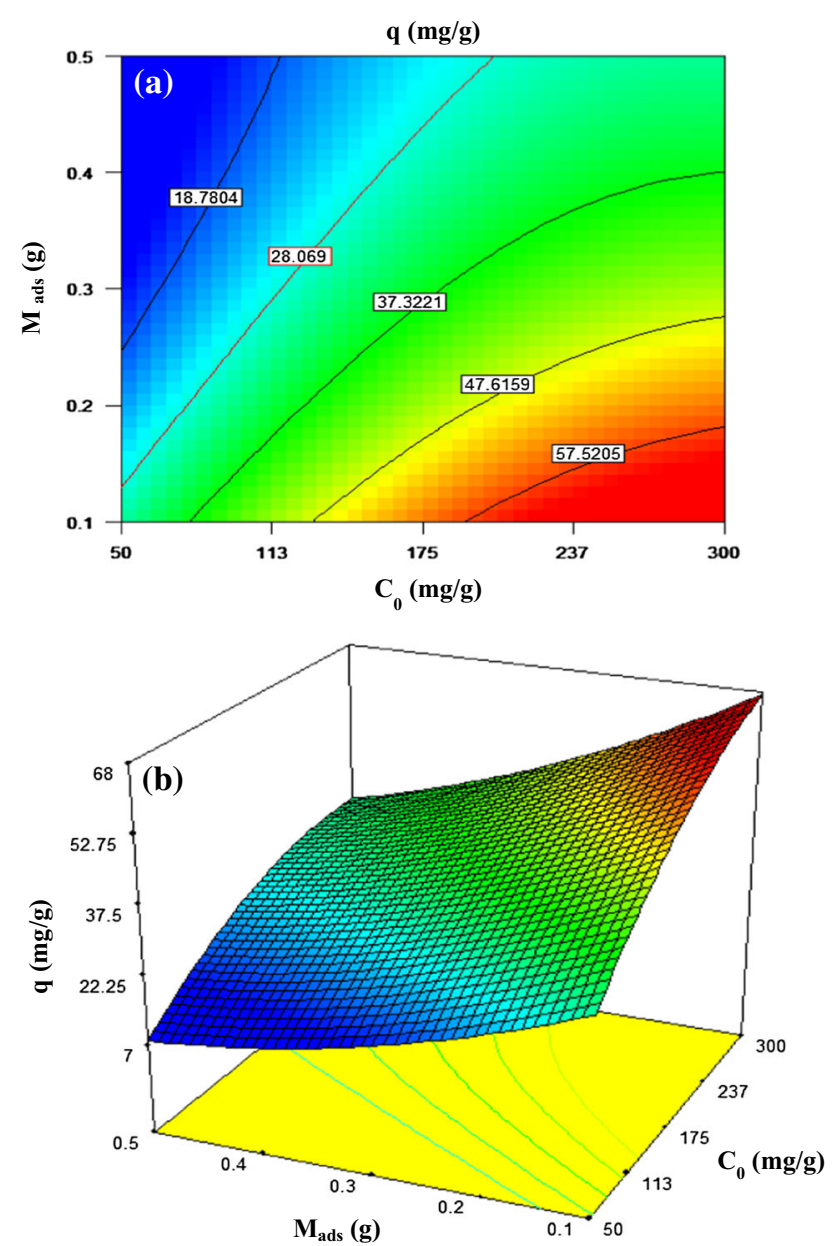

Fig. 8 Three-dimensional plots showing effects of initial cobalt (II) concentration and biomass dosage (BC) holding the temperature at $30{ }^{\circ} \mathrm{C}$ and $\mathrm{pH} 4.8$

The effects of initial cobalt (II) concentration and biomass dosage $(\mathrm{BC})$ can be inferred from the response plot Fig. 8 , holding the temperature at $30{ }^{\circ} \mathrm{C}$ and $\mathrm{pH}$ at 4.8 . The biosorption capacity decreased from 59.13 to $29.64 \mathrm{mg} / \mathrm{g}$ for the $\mathrm{Co}^{2+}$ ions with increasing the biosorbent dosage from 0.1 to 0.5 , respectively. The uptake capacity was calculated at $\mathrm{pH} 4.8$ and initial metal ion concentration $175 \mathrm{mg} / \mathrm{l}$. At higher biosorbent dose the uptake capacity is low, possibly due to the unsaturation of biosorption sites and also due to the particle aggregation. Such aggregation would lead to decrease in total surface area of the biosorbent and an increase in diffusional path length (Singh et al. 2010).

\section{Confirmatory experiments}

Model validations at two experimental combinations were used for validation of the statistical model. In order to compare the experimental results under the optimum condition with the simulated values from the proposed model, experiments were performed in duplicate. Under these conditions, the experimental responses for biosorption capacity were obtained 81.11 and $79.98 \mathrm{mg} / \mathrm{g}$. The results indicate that the experimental values are very close to the predicted values $(80.21 \mathrm{mg} / \mathrm{g})$, and hence, the model is successful in predicting the responses.

\section{Isotherm at optimized condition}

The biosorption isotherms are characterized by definite parameters, whose values express the surface properties and affinity of biosorbent for different heavy metal ions (Bulgariu and Bulgariu 2012). Several isotherm equations have been used for the equilibrium modeling of biosorption systems. In this study, the Langmuir and Freundlich adsorption models were tested to determine the relationship between adsorbed cobalt ions on the algal cell $\left(q_{\mathrm{eq}}\right)$ and unadsorbed cobalt ions in solution $\left(C_{\mathrm{eq}}\right)$. The most widely used isotherm equation for modeling equilibrium is the Langmuir equation, based on the assumption that there is a finite number of binding sites which are homogeneously distributed over the adsorbent surface, these binding sites have the same affinity for adsorption of a single molecular layer and there is no interaction between adsorbed molecules (Ozer et al. 2008). The linear form of Langmuir isotherm is given by the following equation:

$\frac{1}{q_{\mathrm{eq}}}=\frac{1}{b q_{\mathrm{m}} C_{\mathrm{eq}}}+\frac{1}{q_{\mathrm{m}}}$

where $q_{\mathrm{eq}}(\mathrm{mg} / \mathrm{g})$ is the amount adsorbed at the equilibrium, $C_{\mathrm{eq}}(\mathrm{mg} / \mathrm{l})$ the equilibrium concentration, $q_{\mathrm{m}}(\mathrm{mg} / \mathrm{g})$ is the Langmuir constant representing the maximum monolayer adsorption capacity, and $b(1 / \mathrm{mg})$ is the Lang- 
Table 7 Adsorption isotherm parameters for Co (II) biosorption on Mg-treated Sargassum

\begin{tabular}{|c|c|c|c|c|c|c|c|c|}
\hline \multirow[t]{2}{*}{$\mathrm{T}\left({ }^{\circ} \mathrm{C}\right)$} & \multicolumn{4}{|c|}{ Langmuir constants } & \multicolumn{4}{|c|}{ Freundlich constants } \\
\hline & $q_{\mathrm{m}}(\mathrm{mg} / \mathrm{g})$ & $b(1 / \mathrm{mg})$ & $R^{2}$ & $\chi^{2}$ & $k$ & $n$ & $R^{2}$ & $\chi^{2}$ \\
\hline 15 & 76.336 & 0.025 & $0.9,728$ & 1.471 & 7.485 & 2.399 & 0.9987 & 0.038 \\
\hline 23 & 78.740 & 0.024 & 0.9719 & 1.545 & 7.248 & 2.337 & 0.9988 & 0.037 \\
\hline 30 & 80.645 & 0.023 & 0.9728 & 1.638 & 7.049 & 2.285 & 0.9988 & 0.036 \\
\hline 38 & 83.333 & 0.022 & 0.9728 & 1.680 & 6.833 & 2.230 & 0.9989 & 0.037 \\
\hline 45 & 85.470 & 0.021 & 0.9748 & 2.142 & 6.653 & 2.185 & 0.9990 & 0.036 \\
\hline
\end{tabular}

muir constant related to energy of adsorption and the affinity of the binding sites (Bhatnagar et al. 2010; Khani 2011). The equilibrium parameters $\left(q_{\mathrm{m}}\right.$ and $\left.b\right)$ are determined from the linear plot of $1 / q_{\text {eq }}$ versus $1 / C_{\text {eq }}$.

The adsorption data were also analyzed by Freundlich model. The Freundlich expression is used for heterogeneous surface energy term. The Freundlich isotherm equation is an exponential equation and therefore assumes that as the adsorbate concentration increases, the concentration of adsorbate on the adsorbent surface also increases (Ozer et al. 2008). Freundlich equation commonly presented as below.

$q_{\mathrm{eq}}=k C_{\mathrm{eq}}^{\frac{1}{n}}$

The logarithmic form of Freundlich model is given by following equation:

$\log q_{\mathrm{eq}}=\log k+\frac{1}{n} \log C_{\mathrm{eq}}$

where $k$ and $n$ are constants related to the adsorption capacity and intensity of the adsorbent characteristics of the system, respectively (Singh et al. 2010). The fractional values of biosorbent surface simultaneously indicate a favorable biosorption of metal ions onto biomass (Bulgariu and Bulgariu 2012). The plots of $\log q_{\mathrm{eq}}$ versus $C_{\mathrm{eq}}$ determine values of $1 / n$ and $k$.

The biosorption isotherm for the sorption on cobalt on Mg-treated biomass was obtained at different temperature and constant optimized conditions determined by DesignExpert software $\left(\mathrm{pH}=7\right.$ and $\left.M_{\text {ads }}=0.1\right)$. The results of the adsorption isotherms for the cobalt ions at five different temperatures versus initial concentrations of 50, 113, 175, 238, and $300 \mathrm{mg} / \mathrm{g}$ are presented in Table 7.

Error analysis $\left(\chi^{2}\right)$ was used for evaluating applicability of each model. The nonlinear Chi-square test statistic $\left(\chi^{2}\right)$ (the best-fit isotherm) is based on the following equation (Ghaedi et al. 2014):

$\chi^{2}=\sum \frac{\left(q_{\mathrm{e}, \mathrm{exp}}-q_{\mathrm{e}, \mathrm{cal}}\right)^{2}}{q_{\mathrm{e}, \mathrm{cal}}}$

where $q_{\mathrm{e}, \exp }$ and $q_{\mathrm{e}, \mathrm{cal}}$ are experimental and calculated adsorption capacity value, respectively. Non-applicability of each model makes possible larger $\chi^{2}$ value. In principle, the model with the higher $R^{2}$ and smaller $\chi^{2}$ value represents the better fit of the model with the experimental data. The higher correlation coefficients values $\left(R^{2}\right)$ and smaller $\chi^{2}$ value as shown in Table 7 verifies that Freundlich model is more suitable than Langmuir for adsorption equilibrium of cobalt. The better fit of equilibrium data to the Freundlich equation refers the multilayer sorption of the cobalt ions on the biosorbent (Singh et al. 2010). However, Langmuir isotherm had a better fit in some studies (Suhasini et al. 1999; Bishnoi et al. 2007; Bulgariu and Bulgariu 2012). Some authors explain that Langmuir isotherm corresponds to a dominant ion exchange mechanism while the Freundlich isotherm shows adsorption-complexation reactions taking place in the adsorption process (Khani 2011). The result in Table 7 shows that $n$ values related to Freundlich isotherm are greater than unity representing favorable biosorption conditions and formation of relatively stronger bonds between adsorbent and adsorbate (Dahiya et al. 2008; Ozer et al. 2008). 


\section{Conclusion}

In the study, central composite design (CCD) was used for the RSM in the experimental design and proved to be an efficient method for testing the effect of operating conditions and their interactions on cobalt uptake by the brown algae Sargassum sp. The interactive effects of five independent factors: initial $\mathrm{pH}$ of solution, initial concentration cobalt (II), temperature, biosorbent dosage, and biomass treatment on the biosorption capacities were estimated. A reduced quadratic model was obtained for predicting the biosorption capacity. ANOVA results confirmed that there was significant agreement between the model and experimental data. The optimum biosorption conditions were determined as Mg-treated biomass, initial $\mathrm{pH} 7.0$, temperature $45^{\circ} \mathrm{C}$, biosorbent dosage $0.1 \mathrm{~g}$, and initial cobalt (II) ion concentration $300 \mathrm{mg} / \mathrm{l}$. At optimum biosorption conditions, the biosorption capacity of Mg-treated biomass for cobalt (II) ions was found to be $80.27 \mathrm{mg} / \mathrm{g}$. These findings showed the effectiveness of $\mathrm{Mg}$ as a surface modifier enhancing the biosorption capacity of brown alga Sargassum sp. for cobalt ion. Future research studying the effectiveness of this surface modifier on other metal ions is recommended.

Acknowledgments Special thanks to Dr. S.M. Mousavi and M. Jalaeian for their help to accomplish this work. The authors are grateful to Stat-Ease, Minneapolis, USA, for the provision of the Design-Expert package.

\section{Glossary}

\begin{tabular}{|c|c|}
\hline & The Langmuir constant $(1 / \mathrm{mg})$ \\
\hline$b_{0}, b_{i}$ and $b_{i j}$ & $\begin{array}{l}\text { Linear and quadratic interaction } \\
\text { coefficients, } i \text { and } j=1-5\end{array}$ \\
\hline$C$ & Metal ion concentration at any time $(\mathrm{mg} / \mathrm{l})$ \\
\hline$C_{0}$ & Initial metal ion concentration $(\mathrm{mg} / \mathrm{l})$ \\
\hline$C_{\mathrm{eq}}$ & $\begin{array}{l}\text { Residual metal ion concentration at } \\
\text { equilibrium }(\mathrm{mg} / \mathrm{l})\end{array}$ \\
\hline C.I. & Confidence interval $(-)$ \\
\hline C.V. & Coefficient variation $(-)$ \\
\hline$k$ & Adsorption capacity $(-)$ \\
\hline$n$ & Biosorption intensity (-) \\
\hline P.I. & Prediction interval (-) \\
\hline . & $\begin{array}{l}\text { Amount of biosorbed metal per } \mathrm{g} \text { of } \\
\text { biosorbent at any time }(\mathrm{mg} / \mathrm{g})\end{array}$ \\
\hline
\end{tabular}

The amount of biosorbed metal per unit weight of biosorbent at equilibrium $(\mathrm{mg} / \mathrm{g})$ Experimental amount of biosorbed metal per unit weight of biosorbent at equilibrium $(\mathrm{mg} / \mathrm{g})$

$q_{\mathrm{m}} \quad$ Maximum capacity of biosorbent

$q_{\text {pre }} \quad$ Predicted amount of biosorbed metal per unit weight of biosorbent at equilibrium by software $(\mathrm{mg} / \mathrm{g})$

$R^{2} \quad$ Correlation coefficient

$R_{\text {adj }}^{2}$

$M_{\text {ads }}$

$t$

Adjusted correlation coefficient

Amount of biosorbent $(\mathrm{g})$

Time (min)

Independent variable: $x_{1}=T x_{2}=C_{0}$, $x_{3}=M_{\mathrm{ads}}, x_{4}=\mathrm{pH}, x_{5}=$ type of algae

Response (-)

Volume of the solution (1)

Solution temperature $\left({ }^{\circ} \mathrm{C}\right)$

Nonlinear Chi-square

\section{References}

Ahmadpour A, Tahmasbi M, Rohani Bastami T, Amel Besharati J (2009) Rapid removal of cobalt ion from aqueous solutions by almond green hull. J Hazard Mater 166:925-930

And Kuyucak N, Volesky B (1989) Accumulation of cobalt by marine algae. Biotechnol Bioeng 33(7):809-814

Annadurai G, Juang RS, Lee DJ (2003) Adsorption of heavy metals from water using banana and orange peels. Water Sci Technol 47(1):185-190

Bhatnagar A, Minocha AK, Sillanpaa M (2010) Adsorptive removal of cobalt from aqueous solution by utilizing lemon peel as biosorbent. Biochem Eng J 48:181-186

Bishnoi NR, Kumar R, Kumar S, Rani S (2007) Biosorption of Cr(III) from aqueous solution using algal biomass Spirogyra spp. J Hazard Mater 145:142-147

Bulgariu D, Bulgariu L (2012) Equilibrium and kinetics studies of heavy metal ions biosorption on green algae waste biomass. Bioresour Technol 103:489-493

Chen JP, Hong L, Wu S, Wang L (2002) Elucidation of interactions between metal ions and $\mathrm{Ca}$ alginate-based ion-exchange resin by spectroscopic analysis and modeling simulation. Langmuir 18:9413-9421

Dahiya S, Tripathi RM, Hegde AG (2008) Biosorption of heavy metals and radionuclide from aqueous solutions by pre-treated arca shell biomass. J Hazard Mater 150:376-386 
Davis TA, Volesky B, Mucci A (2003) A review of the biochemistry of heavy metal biosorption by brown algae. Water Res 37:4311-4330

Demim S, Drouiche N, Aouabed A, Benayad T, Couderchet M, Semsari S (2014) Study of heavymetal removal from heavy metal mixture using the CCD method. J Ind Eng Chem 20:512-520

Deng L, Su Y, Su H, Wang X, Zhu X (2006) Biosorption of copper(II) and lead(II) from aqueous solutions by nonliving algae Cladophorafascicularis: equilibrium, kinetics and environmental effects. Adsorption 12(4):267-277

Diniz V, Volesky B (2006) Desorption of lanthanum, europium and ytterbium from Sargassum. Sep Purif Technol 50:71-76

Figueira MM, Volesky B, Mathieu HJ (1999) Instrumental analysis study of iron species biosorption by Sargassum biomass. Environ Sci Technol 33:1840-1846

Freitas O, Delerue-Matos C, Boaventura R (2009) Optimization of $\mathrm{Cu}$ (II) biosorption onto Ascophyllumnodosum by factorial design methodology. J Hazard Mater 167:449-454

Ghaedi M, Hajati S, Karimi F, Barazesh B, Ghezelbash G (2013a) Equilibrium, kinetic and isotherm of some metal ion biosorption. J Ind Eng Chem 19:987-992

Ghaedi M, Montazerzohori M, Nejati Biyareh M, Mortazavi K, Soylak M (2013b) Chemically bonded multiwalled carbon nanotubes as efficient material for solid phase extraction of some metal ions in food samples. Intern J Environ Anal Chem 93(5):528-542

Ghaedi M, Ansari A, Habibi MH, Asghari AR (2014) Removal of malachite green from aqueous solution by zinc oxide nanoparticle loaded on activated carbon: kinetics and isotherm study. J Ind Eng Chem 20:17-28

Ghorbani F, Younesi H, Ghasempouri SM, Zinatizadeh AA, Amini M, Daneshi A (2008) Application of response surface methodology for optimization of cadmiumbiosorption in an aqueous solution by Saccharomyces cerevisiae. Chem Eng J 145:267-275

Haug A (1961) The affinity of some divalent metals to different types of alginates. Acta Chem Scand 15:1794-1795

Khani MH (2011) Statistical analysis and isotherm study of uranium biosorption by Padina sp. algae biomass. Environ Sci Pollut Res 18:790-799

Khani MH, Keshtkar AR, Meysami B, Zarea MF, Jalali R (2006) Biosorption of uranium from aqueous solutions by nonliving biomass of marine algae cystoseira indica. Electron J Biotechnol 9(2):100-106

Khani MH, Keshtkar AR, Ghannadi M, Pahlavanzadeh H (2008) Equilibrium, kinetic and thermodynamic study of the biosorption of uranium onto cystoseriaindica algae. J Hazard Mater 150:612-618

Khodadoust S, Ghaedi M, Sahraei R, Daneshfar A (2014) Application of experimental design for removal of sunset yellow by copper sulfide nanoparticles loaded on activated carbon. J Ind Eng Chem 20:2663-2670
Kleinubing SJ, da Silva EA, da Silva MGC, Guibal E (2011) Equilibrium of $\mathrm{Cu}(\mathrm{II})$ and $\mathrm{Ni}(\mathrm{II})$ biosorption by marine alga Sargassum filipendula in a dynamic system: competitiveness and selectivity. Bioresour Technol 102:4610-4617

Li X, Tang Y, Cao X, Lu D, Luo F, Shao W (2008) Preparation and evaluation of orange peel cellulose adsorbents for effective removal of cadmium, zinc, cobalt and nickel. Colloids Surf A 317:512-521

Mafi Gholami R, Mousavi SM, Borghei SM (2012) Process optimization and modeling of heavy metals extraction from a molybdenum rich spent catalyst by Aspergillus niger using response surface methodology. J Ind Eng Chem $18: 218-224$

Maresova J, Pipiska M, Rozloznik M, Hornik M, Remenarova L, Augustin J (2011) Cobalt and strontium sorption by moss biosorbent: modeling of single and binary metal systems. Desalination 266:134-141

Omidvar L, Pahlavanzadeh H, Mousavi SM (2014) Statistical evaluation of a liquid desiccant dehumidification system using RSM and theoretical study based on the effectiveness NTU model. J Ind Eng Chem 20:2975-2983

Ozdemir G, Ceyhan N, Manav E (2005) Utilization of an exopolysaccharide produced by Chryseomonas luteola TEM05 in alginate beads for adsorption of cadmium and cobalt ions. Bioresour Technol 96(15):1677-1682

Ozer A, Gurbuz G, Calimli A, Korbahti BK (2008) Investigation of nickel(II) biosorption on Enteromorphaprolifera: optimization using response surface analysis. J Hazard Mater 152:778-788

Pahlavanzadeh H, Keshtkar AR, Safdari J, Abadi Z (2010) Biosorption of nickel(II) from aqueous solution by brown algae: equilibrium, dynamic and thermodynamic studies. J Hazard Mater 175:304-310

Papageorgiou SK, Katsaros FK, Kouvelos EP, Nolan JW, Le Deit H, Kanellopoulos NK (2006) Heavy metal sorption by calcium alginate beads from Laminaria digitata. J Hazard Mater 137:1765-1772

Roosta M, Ghaedi M, Daneshfar A, Sahraei R (2014) Experimental design based response surface methodology optimization of ultrasonic assisted adsorption of safaranin $\mathrm{O}$ by tin sulfide nanoparticle loaded on activated carbon. Spectrochim Acta Part A 122:223-231

Sheng PX, Ting Y, Chen JP, Hong L (2004) Sorption of lead, copper, cadmium, zinc, and nickel by marine algal biomass: characterization of biosorptive capacity and investigation of mechanisms. J Colloid Interface Sci 275:131-141

Singh R, Chadetrik R, Kumar R, Bishnoi K, Bhatia D, Kumar A, Bishnoi NR, Singh N (2010) Biosorption optimization of lead(II), cadmium(II) and copper(II) using response surface methodology and applicability in isotherms and thermodynamics modeling. J Hazard Mater 174:623-634 
Suhasini IP, Sriram G, Asolekar SR, Sureshkumar GK (1999) Biosorptive removal and recovery of cobalt from aqueous systems. Process Biochem 34:239-247

Sun X-F, Wang S-G, Liu X-W, Gong W-X, Bao N, Gao B-Y (2008) Competitive biosorption of zinc(II) and cobalt(II) in single- and binary-metal systems by aerobic granules. J Colloid Interface Sci $324: 1-8$
Tsezos M, Volesky B (1981) Biosorption of uranium and thorium. Biotechnol Bioeng 23(3):583-604

Vijayaraghavan K, Jegan J, Palanivelu K, Velan M (2005) Biosorption of cobalt(II) and nickel(II) by seaweeds: batch and column studies. Sep Purif Technol 44:53-59 